\title{
Intertemporal substitution in import demand and habit formation
}

Citation for published version (APA):

Croix de la, D., \& Urbain, J. R. Y. J. (1996). Intertemporal substitution in import demand and habit formation. METEOR, Maastricht University School of Business and Economics. METEOR Research Memorandum No. 004 https://doi.org/10.26481/umamet.1996004

Document status and date:

Published: 01/01/1996

DOI:

10.26481/umamet.1996004

Document Version:

Publisher's PDF, also known as Version of record

\section{Please check the document version of this publication:}

- A submitted manuscript is the version of the article upon submission and before peer-review. There can be important differences between the submitted version and the official published version of record.

People interested in the research are advised to contact the author for the final version of the publication, or visit the DOI to the publisher's website.

- The final author version and the galley proof are versions of the publication after peer review.

- The final published version features the final layout of the paper including the volume, issue and page numbers.

Link to publication

\footnotetext{
General rights rights.

- You may freely distribute the URL identifying the publication in the public portal. please follow below link for the End User Agreement:

www.umlib.nl/taverne-license

Take down policy

If you believe that this document breaches copyright please contact us at:

repository@maastrichtuniversity.nl

providing details and we will investigate your claim.
}

Copyright and moral rights for the publications made accessible in the public portal are retained by the authors and/or other copyright owners and it is a condition of accessing publications that users recognise and abide by the legal requirements associated with these

- Users may download and print one copy of any publication from the public portal for the purpose of private study or research.

- You may not further distribute the material or use it for any profit-making activity or commercial gain

If the publication is distributed under the terms of Article $25 \mathrm{fa}$ of the Dutch Copyright Act, indicated by the "Taverne" license above, 



\title{
Intertemporal substitution in import demand and habit formation*
}

\author{
David de la Croix ${ }^{1} \quad$ Jean-Pierre Urbain ${ }^{2}$
}

First draft: February 1995

This version: December 1995

\begin{abstract}
To study non-durable import demand, we extend previous work done by Clarida (1994) and Ceglowski (1991) by considering a two-good version of the life cycle model in which we introduce time-nonseparability in the households' preferences. The model is estimated using quarterly data for US and France. Using the information contained in the observed stochastic and deterministic trends, we derive a cointegration restriction used to estimate curvature parameters of the instantaneous utility function. The remaining parameters are estimated in a second step by GMM. The constancy of the different parameters is investigated, both in the long and the short-run. Habit formation turns out to be an important factor of import demand.
\end{abstract}

JEL Classification numbers: F41, D12

*We would like to thank Eric Dor, François Langot, Franz Palm, Daniel Weiserbs and the participants to the HCM workshop in Aarhus and to the 1995 Annual Meeting of the European Economic Association in Prague for helpful comments and discussion. We also thank Janet Ceglowski for making her data available to us.

1 National Fund for Scientific Research (Belgium) and University of Louvain, Department of Economics, Place Montesquieu 3, B-1348 Louvain-la-Neuve, E-Mail: delacroix@ires.ucl.ac.be. This research has been supported by a grant "actions de recherche concertées" 93/98-162 of the Ministery of scientific research (Belgian French speaking community).

2 University of Limburg, Department of Quantitative Economics, P.O. Box 616, 6200 MD Maastricht, The Netherlands, E-Mail: j.urbain@ke.rulimburg.nl. 


\section{Introduction}

A large number of empirical applications on trade-balance and imports are now explicitly drawn from the optimality conditions of an inter-temporal maximization program, under the assumption of rational expectations. These models capture explicitly a simple idea that is missing in earlier work albeit central to macroeconomics: there is an ever present competition of resources between today and future periods. As far as imports are concerned, such models allow to consider, along with the relative price of imports, the real interest rates as a second channel through which policy could affect the trade balance (Ceglowski, 1991). ${ }^{1}$

Taking so explicitly interest rates into account is in sharp contrast with most of the existing empirical literature on import demand which is mainly "atheoretical" in the sense that the so-called import demand models are derived from a pure empirical exercise (see for example Urbain (1992) and the references therein). Looking back to the existing literature dealing with the empirical modelling of trade flows, and more particularily of import demand, one can roughly derive two general classes of studies.

The first part, and certainly the most important one, of the applied econometrics literature dealing with import demand models has been based on what has often been called pseudo-reduced form models (see the survey of Goldstein and Khan (1985)) or empirically derived dynamic specifications (see inter alia Urbain (1992), Asseery and Peel (1991), Mah (1994)). While these models usually have "naïve" theoretical foundations based on some form of the imperfect substitutes model surveyed by Goldstein and Khan (1985), they nevertheless have the advantage of enabling the time series properties of the data to be fully taken into account so that the resulting models (if derived within a coherent modelling framework) are often statistically well specified (see Urbain,1995).

The second class of studies is implicitly motivated by the Lucas (1976) critique which argues that the parameters of traditional macroeconometric models depend crucially on parameters governing the processes used to form agents' expectations and are unlikely to remain stable in a changing economic environment. As a response to this, a number of papers have focused on the estimation of theoretical intertemporal optimisation models with rational expectations assumed to have an explicit and direct structural interpretation (see inter alia Ceglowski (1991), Clarida (1994), Kollintzas and Husted (1984), Husted and Kollintzas (1987), Gagnon (1988)). Although these models have some strong theoretical motivation, it must be pointed out that the statistical properties of the time series data used are often not taken into account ${ }^{2}$ or at least not fully exploited. One of the interesting aspect of working in this set-up is that a number of other factors affecting trade balance, such as real interest rates changes, emerge from the analysis.

This paper integrates the time series characteristics of the data into the study of a theoretical based dynamic model for consumer non-durable imports. If the driving forces of the economy are indeed non-stationary processes, as it is now almost well accepted in the literature, then intertemporal optimization models lead in general to two types of testable restrictions (see for example Canova, Finn and Pagan, 1992). First, there are long-run restrictions reflecting the fact that there are generally more variables to be

\footnotetext{
${ }^{1}$ A related question is to know to what extent the very high interest rates experienced by Europe since the beginning of the eighties could be held responsible for the existing surplus of current accounts.

${ }^{2}$ An exception being the paper by Clarida (1994).
} 
modelled than there are independent forcing processes. Second, there are restrictions upon the (short-run) dynamics of the system.

In general, long-run restrictions are not rejected by the data. For instance, with strongly separable addilog preferences, the intertemporal import demand theory predicts that the $\log$ of demand for import goods, the log of demand for domestic good and the $\log$ of the relative price of imports, if $\mathrm{I}(1)$ processes, are cointegrated. This long-run relation describes the potential substitution between current imports and current consumption of domestic goods. Clarida (1994) find strong support in the data for such cointegration vectors. As stressed already by Ogaki (1992), the interest of the approach is that the estimated parameters of the cointegration vector are sufficient to identify the curvature parameters of the utility function (i.e., the intertemporal elasticity of substitution for the two goods). It appears that the intertemporal elasticity of substitution for consumer imports is significantly larger than the one for domestic consumption.

Turning our attention to the short-run dynamics, the evidence in favor of the theory is less clear (see Hansen and Singleton (1982) for consumption, Ceglowski (1991) for imports and Otto (1992) for the current account) or not investigated at all. Morevover, the constancy of the short-run parameters is very seldomly analysed. These are important issues since these short-run relations describe the substitution of consumption between two points in time, which is the interesting mechanism of present-value models. Empirical rejection of the validity of these can cast some doubts on the validity of the underlying theoretical model. ${ }^{3}$

The issues that we explore in this paper are threefold: (i) The existing US based empirical analysis of the stationarity restrictions implied by the present-value model has led to the conclusion that the intertemporal elasticity of substitution for non-durables imports is three times the one for domestic goods. We would like to investigate whether this important result is confirmed by French data and whether this long-run information contained in the data can be used to improve our knowledge of the dynamics. (ii) We generalize the set-up used in Ceglowski (1991) and Clarida (1994) in order to allow for a richer dynamic. In particular, we investigate whether introducing intertemporal nonseparability in households utility could be helpful to account for imports dynamics in the face of changes in interest rates. Our intuition is that the pure forward-looking dynamics generated by the basic present-value model is too restrictive and that the introduction of time non-separability introduces richer dynamic structures with some backward-looking elements. (iii) Although often not explicitly investigated, we pay some attention to the empirical success (or failure) of our theoretical specification by investigating the constancy of the deep structural parameters estimates (in the sense of Lucas).

The rationality for introducing time non-separable preferences is to be found in the works of socio-psychologists (see Argyle, 1987) and biologists Helson (1964). The habit formation is one form of time nonseparability which has been extensively studied in consumption theory. The idea dates back to Duesenberry (1949). It amounts basically to assume that tastes are changing and that these changes depend on past decisions (i.e. past consumption levels or expenditures level). If we only consider the recent contributions, Muellbauer (1988), Eichenbaum, Hansen and Singleton (1988), Ferson and Constantinides

\footnotetext{
${ }^{3}$ Effectively, long-run restrictions, such as cointegration restrictions, are not sufficient to provide strong empirical support to a given theoretical model since different theoretical models can lead to similar longrun relations among a given set of variables.
} 
(1991) and Ogaki and Park (1994) find that habit formation helps to account for consumption dynamics. However, up to our knowledge, habit formation has never been introduced in studies of import demand or current account determination. Our purpose is to investigate, in the case of imports, if "ignoring habits or other forms of nonseparability may explain the frequent rejection of the life cycle hypothesis" (Winder and Palm, 1992).

The structure of this paper is as follows. In Section 2 we present the theoretical model, derive the intertemporal substitution properties and point out how one can derive a cointegration restriction from this set-up. Section 3 present the data series and some univariate time series properties. Section 4 reports the estimation results and investigates the parameter constancy issue. A final section concludes.

\section{The model}

The representative household has preferences defined over the services $\tilde{c}_{m}$ and $\tilde{c}_{d}$ provided by the acquisitions of non-durable imported consumption goods $c_{m}$ and non-durable domestic consumption goods $c_{d}$. The purchase of goods is transformed into services according to the following relation:

$$
\tilde{c}_{i t}=\frac{c_{i t}-\gamma_{i} c_{i t-1}}{1-\gamma_{i}}, \quad i=m, d
$$

The parameters $\left.\gamma_{m}, \gamma_{d} \in\right]-1,1[$ measure the extent to which past purchases affect current services. If they are positive, the household is subject to habit formation: the more the consumer has purchased in the previous period, the more he has to purchase in order to attain the same level of satisfaction. A negative $\gamma_{i}$ indicates that the good presents some durability (see e.g. Ferson and Constantinides (1991)): in that case, the accumulation of past flows of purchases contributes to satisfaction. This accumulation is, in our case, limited to one period. Of course, even with non-durables, one cannot fully exclude the presence of the effect of some inventory holdings which could lead to a downward bias in the habit formation parameter estimates. If these parameters are zero, the utility function is time-separable as in Clarida (1994) and Ceglowski (1991). The specific form of the instantaneous utility function of the representative household is:

$$
U\left(\tilde{c}_{d t}, \tilde{c}_{m t}\right)=\sum_{i=m, d} \frac{\exp \left(\mu_{i} t\right)}{1-\alpha_{i}} \tilde{c}_{i t}^{1-\alpha_{i}}
$$

which is a special case of the form used by Eichenbaum, Hansen and Singleton (1988) with no utility for leisure. ${ }^{4}$ The parameters $\alpha_{i}>0$ are called curvature parameters and their inverse can be interpreted as long-run intertemporal elasticities of substitution when $c_{i t}=c_{i t-1}=\tilde{c}_{i t}$. The trend terms $\mu_{i}$ could be interpreted as deterministic technological progresses in the transformation of purchases into services. Let us denote the stock of assets and the labor income of the representative household respectively by $a_{t}$ and $y_{t}$. The representative household selects $\left\{c_{d t}, c_{m t}, a_{t}\right\}$ so as to:

$$
\max \mathrm{E}\left[\sum_{t=s}^{\infty} \theta^{t} U\left(c_{d t}, c_{d t-1}, c_{m t}, c_{m t-1}\right) \mid \Omega_{s}\right] \quad 0<\theta<1
$$

\footnotetext{
${ }^{4}$ The utility function (2) displays strong separability between the two goods. Ogaki (1992) points out that the long-run restriction implied by the maximisation of (2) is still valid under a concave transformation of (2). This is of course not the case for the short-run restrictions.
} 
subject to

$$
\begin{aligned}
& \sum_{i=m, d} p_{i t} c_{i t}+a_{t}=\left(1+r_{t}\right) a_{t-1}+y_{t} \text { for all } t \in[s, \infty[ \\
& a_{s-1}, c_{m s-1}, c_{d s-1} \text { given. }
\end{aligned}
$$

where $p_{i t}$ is the price of good $i, \Omega_{s}$ the information set at time $s$, and $\theta$ the rate of time preference (i.e. the subjective discount rate). Assuming an interior solution, the optimal choice of consumption, import and savings at time $t$ should satisfy:

$$
\begin{aligned}
& p_{i t} \lambda_{t}=\exp \left(\mu_{i} t\right) \tilde{c}_{i t}^{-\alpha_{i}}-\gamma_{i} \theta \exp \left(\mu_{i}(t+1)\right) \mathrm{E}_{t}\left[\tilde{c}_{i t+1}^{-\alpha_{i}}\right] \quad i=m, d \\
& \lambda_{t}=\theta \mathrm{E}_{t}\left[\left(1+r_{t+1}\right) \lambda_{t+1}\right] \\
& \mathrm{E}_{t}\left[\lim _{i \rightarrow \infty} \frac{a_{t+i}}{\prod_{s=t}^{i}\left(1+r_{s}\right)}\right]=0
\end{aligned}
$$

$\lambda$ denotes the Lagrange multiplier associated to the accumulation constraint and $\mathrm{E}_{t}[]=$. $\mathrm{E}\left[. \mid \Omega_{t}\right]$. Equation (5) excludes Ponzi games in which the value of the consumer's debt increases in the limit more rapidly than the compound interest rate.

In this framework, today's consumption of imports can be substituted for future's consumption (intertemporal substitution) or for today's consumption of domestic goods (contemporaneous substitution).

\subsection{Intertemporal substitution}

From (3) and (4), we get:

$$
\tilde{c}_{i t}^{-\alpha_{i}}=\mathrm{E}_{t}\left[\gamma_{i} \theta \exp \left(\mu_{i}\right) \tilde{c}_{i t+1}^{-\alpha_{i}}+\frac{\theta \exp \left(\mu_{i}\right)}{R_{i t+1}}\left(\tilde{c}_{i t+1}^{-\alpha_{i}}-\gamma_{i} \theta \exp \left(\mu_{i}\right) \tilde{c}_{i t+2}^{-\alpha_{i}}\right)\right]
$$

where

$$
R_{i t+1}=\frac{1}{\left(1+r_{t+1}\right)} \frac{p_{i t+1}}{p_{i t}}
$$

for $i=m, d . \quad R_{i}$ are the commodity-specific real discount factors. They represent the opportunity cost of postponing import services (resp. domestic good services) in period $t$ in order to increase import services (resp. domestic good services) in period $t+1$. (6) implies that an increase in the interest rate should induce households to substitute future consumption for current consumption, as long as the parameters $\alpha_{i}$ are positive. If $\gamma_{i}=0$, (6) implies

$$
\mathrm{E}_{t}\left[\frac{\theta \exp \left(\mu_{i}\right)}{R_{i t+1}}\left(\frac{c_{i t+1}}{c_{i t}}\right)^{-\alpha_{i}}-1\right]=0
$$

An increase in the real interest rate by one percent induces a rise in planned consumption of good $i$ by $1 / \alpha_{i}$ percent. To be more precise, this holds only if foresights are perfect. However, as stressed by McLaughlin (1995), $1 / \alpha_{i}$ should produce high quality approximations to the true effects, even with rational expectations and in the absence of consumption insurance. Notice that, following Kim (1993), when within-period preferences are additively separable as in (2), changes in the interest rate and in the commodity 
price have the same inter-temporal substitution effect on a commodity demand. When habit formation is allowed, the effect of a rise in interest rate is more complex, since agents recognize the impact of today's choices on their future tastes. In that case, McLaughlin (1995) shows that $1 / \alpha_{i}$ is an invalid measure of the intertemporal substitution effect.

\subsection{Contemporaneous substitution}

Combining the two equations implied by (3), the relative price between the two goods should equal the marginal rate of substitution of these goods:

$$
\frac{p_{d t}}{p_{m t}}=\exp \left(\left(\mu_{d}-\mu_{m}\right) t\right) \frac{\tilde{c}_{d t}^{-\alpha_{d}}-\gamma_{d} \theta \exp \left(\mu_{d}\right) \mathrm{E}_{t}\left[\tilde{c}_{d t+1}^{-\alpha_{d}}\right]}{\tilde{c}_{m t}^{-\alpha_{m}}-\gamma_{m} \theta \exp \left(\mu_{m}\right) \mathrm{E}_{t}\left[\tilde{c}_{m t+1}^{-\alpha_{m}}\right]}
$$

dividing both sides by $\tilde{c}_{d t}^{-\alpha_{d}} \tilde{c}_{m t}^{-\alpha_{m}}$ and taking logs it comes:

$$
\begin{aligned}
& \alpha_{i} \ln \tilde{c}_{m t}-\alpha_{d} \ln \tilde{c}_{d t}-\ln \left(\frac{p_{d t}}{p_{m t}}\right)+\left(\mu_{d}-\mu_{m}\right) t \\
& =\ln \left\{1-\gamma_{m} \theta \exp \left(\mu_{m}\right) \mathrm{E}_{t}\left[\left(\frac{\tilde{c}_{m t}}{\tilde{c}_{m t+1}}\right)^{\alpha_{m}}\right]\right\}-\ln \left\{1-\gamma_{d} \theta \exp \left(\mu_{d}\right) \mathrm{E}_{t}\left[\left(\frac{\tilde{c}_{d t}}{\tilde{c}_{d t+1}}\right)^{\alpha_{d}}\right]\right\}
\end{aligned}
$$

Following the arguments of Ogaki and Park (1994), it can be shown that equation (9) implies that $\ln c_{m t}, \ln \left(p_{d t} / p_{m t}\right)$ and $\ln c_{d t}$ be cointegrated, as long as these variables are integrated processes of order one. This can be intuitively shown using the approximation proposed by Muellbauer (1988):

$$
\ln \left(\frac{x_{t}-\zeta x_{t-1}}{1-\zeta}\right) \approx \operatorname{cst}+\ln x_{t}+\left(\frac{1-\zeta}{\zeta}+g_{x}\right)^{-1} \Delta \ln x_{t}
$$

where $g_{x}$ is the average of $\Delta \ln x_{t}$. Using (10) in (9), it comes:

$$
\begin{aligned}
& \alpha_{m} \ln c_{m t}-\alpha_{d} \ln c_{d t}-\ln \left(\frac{p_{d t}}{p_{m t}}\right)+\left(\mu_{d}-\mu_{m}\right) t \approx \mathrm{cst} \\
& \quad+\ln \left\{1-\gamma_{m} \theta \exp \left(\mu_{m}\right) \mathrm{E}_{t}\left[\left(\frac{c_{m t}-\gamma_{m} c_{m t-1}}{c_{m t+1}-\gamma_{m} c_{m t}}\right)^{\alpha_{m}}\right]\right\}-\alpha_{m}\left(\frac{1-\gamma_{m}}{\gamma_{m}}+g_{m}\right)^{-1} \Delta \ln c_{m t} \\
& -\ln \left\{1-\gamma_{d} \theta \exp \left(\mu_{d}\right) \mathrm{E}_{t}\left[\left(\frac{c_{d t}-\gamma_{d} c_{d t-1}}{c_{d t+1}-\gamma_{d} c_{d t}}\right)^{\alpha_{d}}\right]\right\}+\alpha_{d}\left(\frac{1-\gamma_{d}}{\gamma_{d}}+g_{d}\right)^{-1} \Delta \ln c_{d t}
\end{aligned}
$$

which provides us with a stationary/cointegration restriction, since the right hand-side of (9) is expressed in terms of covariance-stationary variables. Note that, when $\gamma_{i}=0 \forall i$ as in Clarida (1994), using (3) and taking logs leads to

$$
\alpha_{m} \ln c_{m t}-\alpha_{d} \ln c_{d t}-\ln \left(\frac{p_{d t}}{p_{m t}}\right)+\left(\mu_{d}-\mu_{m}\right) t=0
$$

which requires $\ln c_{m t}, \ln \left(p_{d t} / p_{m t}\right)$ and $\ln c_{d t}$ be cointegrated. ${ }^{5}$ Following Clarida (1994), the two remaining common stochastic trends among the three I(1) variables can be identified

\footnotetext{
${ }^{5}$ In Clarida (1994), stationary preference shocks are introduced so that the right-hand-side of (12) is not 0 but is a function of these shocks.
} 
as the log of the marginal utility of wealth and as a permanent technological shock to the supply of imported goods, and henceforth, the relative prices. Clarida proposes also to compute the standard Marshallian price elasticity (at constant total expenditures) and the expenditure elasticity (at constant prices) of the demand for imports:

$$
\begin{gathered}
\eta_{c_{m} \cdot p_{m} / p_{d}}=-\frac{1}{\alpha_{m}}\left[1-\frac{\left(1-\alpha_{m}\right)(1-s)}{\left(\alpha_{m} s / \alpha_{d}\right)+(1-s)}\right] \\
\eta_{c_{m} .\left(c_{d}+p_{m} c_{m} / p_{d}\right)}=\frac{\alpha_{d}}{\alpha_{m}}\left[\frac{1}{s+\left(\alpha_{d} / \alpha_{m}\right)(1-s)}\right]
\end{gathered}
$$

where $s$ is the share of spending that falls on domestic goods.

With $\gamma_{i} \neq 0, i=m, d$, we can no longer express the demand for goods as an explicit function of prices and of the marginal utility of wealth $\lambda_{t}$. The two remaining common stochastic trends can no longer be identified but are still related to the marginal utility of wealth and to the permanent technological shock to the supply of imported goods. We can no longer compute the instantaneous Marshallian elasticities. However, the above elasticities can be interpreted as long-run elasticities if $c_{i t}=c_{i t-1} \forall i, t$.

\section{$3 \quad$ Empirical results}

Our empirical analysis proceeds in three major steps. In the first step, we use the cointegration/stationarity restrictions derived in (11) to estimate the curvature parameters of the instantaneous utility function. Given that these parameters are super-consistently estimated (see Phillips and Hansen, 1990), we fix these parameters at their estimated values and estimate in a second step the remaining parameters of (6) by the Generalized Methods of Moments (Hansen, 1982). The last step of the empirical analysis consists in the investigation of the potential parameter (non)-constancy of our retained specification and estimation results.

The data we use in this paper are quarterly seasonally adjusted data covering the period 70:01-94:01 for France (97 observations) and 67:01-94:03 for the USA (111 observations). Exact data sources are reported in the appendix.

\subsection{Time series properties of the data}

The first step in the analysis is the computation of some standard univariate unit root tests in order to obtain empirical evidence in favor or against the assumption of stochastic trends in our data. This step, although usually considered more as a descriptive step in many empirical analyses is for our purpose of relative importance since the stationarity/cointegration restriction (11) hinges on the assumption that $\ln c_{m t}, \ln \left(p_{d t} / p_{m t}\right)$ and $\ln c_{d t}$ are well described by unit root processes with possible drifts.

Notice that even if all of our data series do not contain unit roots, but some of them are better modelled as trend stationary processes, then a similar stationarity/cointegration restriction can still be derived by introducing concepts such as cotrending and by distinguishing between stochastic and deterministic cointegration following the terminology of 
Table 1: Unit Root Tests

\begin{tabular}{|c|c|c|c|c|c|c|c|c|c|}
\hline & \multirow[t]{2}{*}{ variable } & \multicolumn{4}{|c|}{ Levels } & \multicolumn{4}{|c|}{ 1st diff. } \\
\hline & & det. & $A D F$ & $P P$ & $S P$ & det. & $A D F$ & $P P$ & $S P$ \\
\hline \multirow[t]{10}{*}{ France } & $\ln p_{m t} / p_{d t}$ & cst,trd & -3.13 & -2.89 & -3.51 & $\operatorname{cst}$ & -5.01 & -6.77 & -6.31 \\
\hline & & $\operatorname{cst}$ & -0.84 & -0.92 & & & -4.71 & -6.70 & \\
\hline & $\ln c_{m t}$ & cst,trd & -3.36 & -2.53 & -2.16 & $\operatorname{cst}$ & -4.17 & -8.03 & -8.18 \\
\hline & & $\operatorname{cst}$ & -2.40 & -2.71 & & & -2.69 & -6.14 & \\
\hline & $\ln c_{d t}$ & cst,trd & -2.20 & -3.37 & -1.77 & $\operatorname{cst}$ & -3.62 & -12.58 & -12.05 \\
\hline & & $\operatorname{cst}$ & -2.52 & -4.03 & & & -2.89 & -10.45 & \\
\hline & $R_{m t}$ & cst,trd & -4.95 & -6.36 & -5.77 & $\operatorname{cst}$ & -6.62 & -13.61 & -7.87 \\
\hline & & cst & -3.97 & -5.94 & & & -6.65 & -13.71 & \\
\hline & $R_{d t}$ & cst,trd & -4.40 & -6.09 & -5.54 & $\operatorname{cst}$ & -5.73 & -16.47 & -10.84 \\
\hline & & $\operatorname{cst}$ & -1.42 & -3.13 & & & -5.75 & -16.59 & \\
\hline \multirow[t]{10}{*}{ U.S.A. } & $\ln p_{m t} / p_{d t}$ & cst,trd & -1.73 & -1.44 & -1.76 & $\operatorname{cst}$ & -4.31 & -7.57 & -6.75 \\
\hline & & cst & -1.91 & -1.62 & & & -4.32 & -7.59 & \\
\hline & $\ln c_{m t}$ & cst,trd & -2.54 & -3.15 & -3.12 & $\operatorname{cst}$ & -5.16 & -14.58 & -13.60 \\
\hline & & $\operatorname{cst}$ & -0.35 & -0.80 & & & -4.62 & -13.72 & \\
\hline & $\ln c_{d t}$ & cst,trd & -2.53 & -2.31 & -2.77 & $\operatorname{cst}$ & -4.59 & -11.32 & -12.04 \\
\hline & & $\operatorname{cst}$ & -0.84 & -1.19 & & & -2.84 & -9.00 & \\
\hline & $R_{m t}$ & cst,trd & -3.74 & -6.62 & -6.55 & cst & -6.49 & -17.83 & -8.58 \\
\hline & & cst & -3.56 & -6.49 & & & -6.52 & -17.93 & \\
\hline & $R_{d t}$ & cst,trd & -2.20 & -4.77 & -4.12 & $\operatorname{cst}$ & -5.99 & -16.55 & -7.85 \\
\hline & & cst & -2.09 & -4.29 & & & -6.02 & -16.65 & \\
\hline \multirow[t]{2}{*}{$5 \%$ crit. } & values & cst,trd & -3.44 & -3.44 & -3.60 & $\operatorname{cst}$ & -2.89 & -2.89 & -3.60 \\
\hline & & cst & -2.89 & -2.89 & & & -1.95 & -1.95 & \\
\hline
\end{tabular}


Ogaki and Park (1994). We say that difference stationary processes are deterministically cointegrated if the cointegrating vector(s) annihilates both the linear deterministic trends and the stochastic trend components. If only the stochastic trends are annihilated, we say that the series are stochastically cointegrated, see for example Ogaki (1993b).

Tables 1 presents the outcome of Dickey and Fuller (1979), Phillips and Perron (1988) tests as well as the Schmidt and Phillips (1992) test which has the advantage of being invariant to the specification of the deterministic components. ${ }^{6}$ Critical values for DF and PP statistics are given in Mackinnon (1991) while for SP, these are reported in Schmidt and Phillips (1992). In all cases the test statistics are computed for two different specifications of the deterministic part ("det." in the Table): a constant and a linear time trend (cst,trd) and a constant term alone (cst). The results of these test statistics can be summarized as follows: $\ln c_{d t}, \ln c_{m t}$ and $\ln p_{m t} / p_{d t}$ seem to be well characterised as $I(1)$ process with drifts. On the other hand, the results for the real interest rates series tend to favour the stationarity assumption, although the French $R_{d t}$ seems to be better described by a trend stationary process.

\subsection{Cointegration analysis}

There exists a wide range of approaches to cointegration testing and estimation, ranging from Engle and Granger (1987) static regressions to multivariate analyses which have a number of advantages in terms of the efficient use of the sample information and the underlying optimal inference that can be conducted. However, these are characterized by particular maintained assumptions which we cannot retain for our analysis. For example, the Johansen (1991) MLE framework assumes that the data are generated by a finite order (linear) Gaussian VAR model. Given our theoretical set-up, this assumption can clearly not be used. An alternative is therefore to use asymptotically median-unbiased estimators that do not require specific parametric representations of the short-run dynamics and that nevertheless lead to optimal inference. In this paper we use the fully modified ordinary least squares estimators (FMOLS) proposed by Phillips and Hansen (1990) and Hansen (1992a) based on semi-parametric corrections for endogeneity and serial correlation which in our case would stem from the presence of $\Delta \ln c_{m t}$ and $\Delta \ln c_{d t}$ in the r.h.s. of (11). ${ }^{7}$ This FMOLS estimator yields asymptotically optimal estimates of the non-stationary components $^{8}$ and is asymptotically equivalent to full information maximum likelihood parametric estimators for a rather large class of innovations processes. Although it is difficult to formally demonstrate that the process underlying the r.h.s. of (11) satisfies the usual conditions required for the applicability of these non-parametric corrections, we assume that these fully-modified approaches keep their optimal asymptotic properties in our case. As a by product, usual asymptotic theory can be used to conduct inference on

\footnotetext{
${ }^{6}$ For both Phillips-Perron (PP) and Schmidt-Phillips (SP) we use the Newey and West (1987) estimator of the long-run variances with four lags. Notice that the results are rather insensitive to the number of lags actually used. The same lag length is used for the Augmented Dickey Fuller (ADF) tests.

${ }^{7}$ Consequently, while super consistent, we expect OLS static regressions to suffer from second order asymptotic bias (see Phillips and Hansen, 1990) in the sense that the asymptotic distribution of the normalized bias is non-central.

${ }^{8}$ One should note however that this implies that the regressors of our problem form a set of full rank I(1) processes. If the latter asssumption is violated, i.e. if the set also includes several I(0) variables, than, in the linear case at least, the Fully Modified GIVE or GMM estimators recently proposed by Kitamura and Phillips (1994) should be prefered.
} 
Table 2: Cointegration Results - Fully Modified OLS Results

$$
\ln c_{m t}=\operatorname{cst}+\frac{1}{\alpha_{m}} \ln \left(\frac{p_{d t}}{p_{m t}}\right)+\frac{\alpha_{d}}{\alpha_{m}} \ln c_{d t}-\frac{\mu_{d}-\mu_{m}}{\alpha_{m}} \text { trend }+ \text { error }_{t}
$$

\begin{tabular}{lccccccccc}
\hline \hline Country & Kernel & cst. & $-\frac{\mu_{d}-\mu_{m}}{\alpha_{m}}$ & $\frac{1}{\alpha_{m}}$ & $\frac{\alpha_{d}}{\alpha_{m}}$ & $L_{c}$ & $H(0,1)$ & SupF & MeanF \\
\hline France & QS & -0.2373 & 0.0032 & 0.1560 & 3.3431 & 0.341 & $6.762^{*}$ & 7.759 & 3.585 \\
& & $(0.060)$ & $(0.001)$ & $(0.141)$ & $(0.267)$ & & & & \\
& Parz. & -0.2380 & 0.0032 & 0.1592 & 3.3376 & 0.341 & $6.744^{*}$ & 7.587 & 3.573 \\
& & $(0.061)$ & $(0.001)$ & $(0.142)$ & $(0.268)$ & & & & \\
& Bart. & -0.2380 & 0.0032 & 0.1530 & 3.3416 & 0.341 & $6.815^{*}$ & 7.794 & 3.603 \\
& & $(0.060)$ & $(0.001)$ & $(0.141)$ & $(0.267)$ & & & & \\
& QS & -0.0824 & - & 0.4085 & 3.9689 & 0.290 & - & 6.866 & 2.890 \\
& & $(0.007)$ & & $(0.134)$ & $(0.113)$ & & & & \\
& Parz. & -0.0824 & - & 0.4081 & 3.9683 & 0.297 & - & 6.982 & 2.949 \\
& & $(0.007)$ & & $(0.133)$ & $(0.113)$ & & & & \\
& Bart. & -0.0824 & - & 0.4069 & 3.9707 & 0.291 & - & 7.013 & 2.908 \\
& $(0.007)$ & & $(0.133)$ & $(0.112)$ & & & & \\
\hline USA & QS & -0.0404 & -0.0003 & 0.7510 & 2.8523 & 0.275 & 0.022 & 12.884 & 5.359 \\
& $(0.121)$ & $(0.002)$ & $(0.062)$ & $(0.442)$ & & & & \\
& Parz. & -0.0436 & -0.0002 & 0.7514 & 2.8396 & 0.277 & 0.015 & 12.866 & 5.419 \\
& $(0.120)$ & $(0.002)$ & $(0.061)$ & $(0.438)$ & & & & \\
& Bart. & -0.0456 & -0.0002 & 0.7507 & 2.8336 & 0.290 & 0.011 & 12.817 & 5.430 \\
& $(0.121)$ & $(0.002)$ & $(0.062)$ & $(0.441)$ & & & & \\
& QS & -0.0582 & - & 0.7497 & 2.7876 & 0.103 & - & 8.533 & 1.818 \\
& $(0.008)$ & & $(0.061)$ & $(0.053)$ & & & & \\
& Parz. & -0.0582 & - & 0.7510 & 2.8523 & 0.104 & - & 8.381 & 1.786 \\
& $(0.008)$ & & $(0.060)$ & $(0.052)$ & & & & \\
& Bart. & -0.0582 & - & 0.7510 & 2.8523 & 0.103 & - & 8.462 & 1.798 \\
& $(0.007)$ & & $(0.060)$ & $(0.053)$ & & & & \\
\hline \hline
\end{tabular}


the cointegrating vector parameters. For example, the significance of a linear trend in the long-run relation implied by (11) can be tested using fully modified Wald or t-test statistics.

As it is well-known in static cointegration regressions, any variables can theoretically be used as the regressand. Following Clarida (1994) and Ceglowski (1991) we decided to use $\ln c_{m t}$ as regressand. Table 2 reports the cointegration results for France and for the US. Standard errors are reported in parentheses. As pointed out by Haug (1995) and Cappucio and Lubian (1994), the way by which we estimate the long-run covariance matrix used to correct the estimates can play an important role, especially in relatively small sample as the one retained here. We therefore report the FMOLS results for different choices of the kernel: QS, Parz. and Bart., standing respectively for Quadratic Spectral, Parzen and Barlett kernels, see Andrews and Monahan (1992). All our estimates are computed using an automatic plug-in bandwith parameter after VAR prewhitening, which avoids the arbitrariness of chosing a priori the order of the truncation parameter.

$L_{c}$ is Hansen (1992b)'s Lagrange Multiplier test for the null of cointegration against the alternative of no-cointegration based on the constancy of the intercept of the cointegration regression. Asymptotic critical values are reported in Hansen $(1992 \mathrm{~b}) . H(0,1)$ is Park (1990)'s Wald test for the null of deterministic cointegration computed on the residuals from the FMOLS regressions (see Park, 1990, Haug, 1995). ${ }^{9}$ It has an asymptotic chisquare distribution with 1 degree of freedom under the null of deterministic cointegration. Finally, the columns $S u p F$ and Mean $F$ are parameter constancy statistics derived by Hansen (1992b). We come to these statistics later in Section 4.

As can be seen from Table 2, there are some notable differences between the results obtained for France and for the US which call for several comments. Notice however that contrary to the simulation outcomes reported in Haug (1995), the results remain almost unchanged if Parzen or Barlett's kernels are used instead of a Quadratic spectral kernel.

Let us first consider the USA. As shown by the point estimates, standard errors as well as both the $L_{c}$ and $H(0,1)$ statistics, we cannot reject the null hypothesis of deterministic cointegration which implies that the cointegration restriction derived in the preceding section seem to hold with the additional restriction that $\mu_{d}=\mu_{m}$ which stems from the insignificance of the trend term (i.e. the deterministic cointegration restriction). The last two columns show that one cannot reject the null hypothesis of parameter constancy of the long-run relation.

The results for France are less straightforward to interpret. When a linear trend is included in the cointegration regression, it appears from both the point estimate of $-\left(\hat{\mu}_{d}-\hat{\mu}_{m}\right) / \hat{\alpha}_{m}$ and from Park (1990)'s $H(0,1)$ (asymptotically $\chi^{2}(1)$ under the null of deterministic cointegration) that we reject the deterministic cointegration restriction at any reasonable significance level while stochastic cointegration is not rejected ${ }^{10}$ by $L_{c}$. From an economic point of view however, the resulting $1 / \hat{\alpha}_{m}$ is surprisingly low and insignificant using fully modified t-test. On the other hand, the estimation of the model without trend, where we thus impose deterministic cointegration $\left(\mu_{d}=\mu_{m}\right)$, provides more realistic point estimates. This is a typical situation where although in both cases

\footnotetext{
${ }^{9}$ Park's canonical cointegeration regressions were also computed but are not reported since they almost exactly coincide with the results obtained from Phillips-Hansen's FMOLS estimator.

${ }^{10} \mathrm{~A}$ similar rejection of non-cointegration is observed if one computes standard ADF or Phillips-Ouliaris test using OLS cointegration regression.
} 
we cannot reject the null of stochastic cointegration, arguments based on economic theory tend to favor the results generated by a model which seems statistically misspecified. Consequently, we consider both cases in the second step of our analysis in order to investigate the sensitivity of the estimation of the habit formation parameters to the maintained hypothesis about deterministic cointegration. Notice again that there is no sign of parameter non-constancy, and this irrespective of the assumption about the presence of a linear trend. ${ }^{11}$

\subsection{Short-run analysis}

We now proceed to the estimation of $(6)$, in which the curvature parameters are restricted to their point estimates obtained from the cointegration analysis. The robustness of the cointegration results to the choice of the kernel and the Monte Carlo evidence reported in Andrews and Monahan (1992) and Cappucio and Lubian (1994) lead us to select the point estimates obtained with the QS kernel. Given the non-linear dynamic rational expectations formulation of the theoretical model, the non-linear IV version of GMM seems a natural method for estimating the remaining parameters of the Euler equations. In analogy to Engle and Granger (1987) two-step method, we assume that the asymptotic properties of the second step GMM procedure are not affected by the first step estimation since the estimators for $\alpha_{m}$ and $\alpha_{d}$ from cointegrating regressions converge faster than the GMM estimators. The advantages of pursuing a cointegration analysis to identify and estimate the preference parameters from the utility function was first pointed out and discussed in detail by Ogaki (1992) and Ogaki and Park (1994). Basically, these advantages are all related to a substantial gain in robustness against several potential problems such as measurement errors, short-run dynamic misspecification, preference shocks, ... which are known to affect the GMM (Ogaki, 1993a).

Defining $\theta_{m}=\theta \exp \left(\hat{\mu}_{m}\right)$ and $\theta_{d}=\theta \exp \left(\hat{\mu}_{d}\right)$, we use the point estimate of the trend coefficient, $\hat{\mu}_{i}$ to impose:

$$
\theta_{d}=\theta_{m} \exp \left(\hat{\mu}_{d}-\hat{\mu}_{m}\right) .
$$

Denoting $\hat{\alpha}_{i}$ the point estimates obtained from the cointegration analysis and dividing $(6)$ by $\tilde{c}_{i t}^{-\hat{\alpha}_{i}}$ leads to the following estimable form:

$$
1-\gamma_{i} \theta_{i}\left(\frac{c_{i t}-\gamma_{i} c_{i t-1}}{c_{i t+1}-\gamma_{i} c_{i t}}\right)^{\hat{\alpha}_{i}}-\frac{\theta_{i}}{R_{i t+1}}\left(\left(\frac{c_{i t}-\gamma_{i} c_{i t-1}}{c_{i t+1}-\gamma_{i} c_{i t}}\right)^{\hat{\alpha}_{i}}-\gamma_{i} \theta_{i}\left(\frac{c_{i t}-\gamma_{i} c_{i t-1}}{c_{i t+2}-\gamma_{i} c_{i t+1}}\right)^{\hat{\alpha}_{i}}\right)=\eta_{i t+1}
$$

for $i=m, d$ and where

$$
\begin{aligned}
\eta_{i t+1}= & -\gamma_{i} \theta_{i}\left(\frac{c_{i t}-\gamma_{i} c_{i t-1}}{c_{i t+1}-\gamma_{i} c_{i t}}\right)^{\hat{\alpha}_{i}}-\frac{\theta_{i}}{R_{i t+1}}\left(\left(\frac{c_{i t}-\gamma_{i} c_{i t-1}}{c_{i t+1}-\gamma_{i} c_{i t}}\right)^{\hat{\alpha}_{i}}-\gamma_{i} \theta_{i}\left(\frac{c_{i t}-\gamma_{i} c_{i t-1}}{c_{i t+2}-\gamma_{i} c_{i t+1}}\right)^{\hat{\alpha}_{i}}\right) \\
& +\mathrm{E}_{t}\left[\gamma_{i} \theta_{i}\left(\frac{c_{i t}-\gamma_{i} c_{i t-1}}{c_{i t+1}-\gamma_{i} c_{i t}}\right)^{\hat{\alpha}_{i}}-\frac{\theta_{i}}{R_{i t+1}}\left(\left(\frac{c_{i t}-\gamma_{i} c_{i t-1}}{c_{i t+1}-\gamma_{i} c_{i t}}\right)^{\hat{\alpha}_{i}}-\gamma_{i} \theta_{i}\left(\frac{c_{i t}-\gamma_{i} c_{i t-1}}{c_{i t+2}-\gamma_{i} c_{i t+1}}\right)^{\hat{\alpha}_{i}}\right)\right]
\end{aligned}
$$

\footnotetext{
${ }^{11}$ The approach we followed implicitly assumes that there is only one cointegrating vectors. Although not reported, Johansen's Trace test does not provide evidence in favour of a second cointegrating vector for both countries. Moreover, in both cases, weak exogeneity of $\ln c_{d t}$ and $\ln \left(p_{m t} / p_{d t}\right)$ is rejected by the data.
} 
which involves only stationary variables. When the two error terms are evaluated at the true value of the parameters, we have by assumption

$$
\mathrm{E}\left[\left(\eta_{m t+1} \eta_{d t+1}\right)^{\prime} \mid \Omega_{t}\right]=0 .
$$

Let $I_{t}$ be a subset of $\Omega_{t}$ including stationary variables observable by the econometrician. The moment restrictions used for the GMM estimation of the parameters can be summarized as

$$
\mathrm{E}\left[\left(\eta_{m t+1} \eta_{d t+1}\right)^{\prime} \otimes I_{t}\right]=0
$$

The two equations are thus estimated jointly with the adequate cross restrictions. Since the error term presents a MA(1) structure, the instruments are lagged once more than in a standard life cycle model. (In the no habit formation case, $\eta_{m t}$ and $\eta_{d t}$ are serially uncorrelated.) As discussed in Hall (1993) and Ogaki (1993a), the GMM often appears to be sensitive to the chosen instrument set. In particular, for a fixed sample size, increasing the number of instruments increases the number of useful overidentifying restrictions but, on the other hand, may introduce substantial bias in the estimates of the coefficients. Accordingly, we define the following instrument sets: a minimalist one, containing a constant and the lagged interest rate, a medium-sized set, and a wider one including past levels of expenditures growth:

$$
\begin{aligned}
& I_{1 t}=\left\{\text { constant }, r_{t-1}\right\}, \\
& I_{2 t}=\left\{p_{d t-1} / p_{d t-2}, p_{m t-1} / p_{m t-2}, \text { trend, trend }{ }^{2}, R_{m t-1}, R_{d t-1}\right\}, \\
& I_{3 t}=I_{2 t} \bigcup\left\{c_{m t-1} / c_{m t-2}, c_{d t-1} / c_{d t-2}\right\} .
\end{aligned}
$$

As suggested by Kocherlakota (1990) and Nelson and Startz (1990), we iterate on the weighting matrix (i.e. the inverse of the covariance matrix of the orthogonality conditions) in order to improve the properties of the estimators in our small sample. For France, two different estimates of the curvature parameters are used: with and without trend in the long-run. Indeed, from the first step, we know that the trend is statistically significant. However, the economic interpretation of the trend may seem difficult. For this reason, we have also estimated the model with the point estimates of $\alpha_{m}$ and $\alpha_{d}$ when we impose $\mu_{d}=\mu_{m}$ (no trend). Note that $\theta_{m}=\theta_{d}$ in the estimations without trend.

Table 3 presents the results. Absolute t-values are reported in parentheses. These are built on the basis of the heteroscedastic-consistent covariance matrix of Newey and West (1987). $J$ is Hansen (1982)'s test for overidentifying restrictions, asymptotically $\chi^{2}$ distributed with $q$ degrees of freedom, where $q$ is the number of overidentifying restrictions. Corresponding P-values are reported between brackets. $L R_{\gamma_{m}=\gamma_{d}=0}$ is a quasi likelihood ratio test for the absence of habit formation, i.e., for $H_{0}: \gamma=\gamma_{d}=0$. As suggested by Gallant (1987), it is computed as the normalized difference between the constrained objective function and the unconstrained one. The constrained estimation is computed with the weighting matrix provided by the unconstrained estimation. SupLR is the supremum of the sequence of the quasi likelihood ratio type test for parameter constancy suggested by Andrews (1993). The critical values and the full sequence of these likelihood ratio test statistics are presented and discussed in the next section.

The main conclusions of the GMM estimation are the following:

- Hansen's $J$ test measures the extent to which the residuals are effectively orthogonal to the instrument set. It can be seen as a global specification test. The numbers of 
Table 3: GMM estimates

\begin{tabular}{lccccccccc}
\hline \hline country & tr. & $I_{t}$ & $q$ & $\theta_{m}$ & $\gamma_{m}$ & $\gamma_{d}$ & $J_{\text {test }}$ & $L R_{\gamma_{m}=\gamma_{d}=0}$ & SupLR \\
\hline France & $\mathrm{y}$ & $I_{1 t}$ & 1 & 0.975 & 0.58 & 0.41 & 1.18 & 4.93 & N.A. \\
& & & & $(8.85)$ & $(4.58)$ & $(2.51)$ & {$[0.28]$} & {$[0.08]$} & \\
& $\mathrm{y}$ & $I_{2 t}$ & 11 & 1.053 & 0.42 & 0.23 & 12.7 & 7.74 & 85.4 \\
& & & & $(33.7)$ & $(3.07)$ & $(1.87)$ & {$[0.31]$} & {$[0.02]$} & \\
& $\mathrm{y}$ & $I_{3 t}$ & 15 & 1.065 & 0.28 & 0.04 & 16.5 & 5.25 & 102.3 \\
& & & & $(68.9)$ & $(2.49)$ & $(0.55)$ & {$[0.35]$} & {$[0.07]$} & \\
& $\mathrm{n}$ & $I_{1 t}$ & 1 & 0.968 & 0.71 & 0.52 & 0.55 & 3.69 & N.A. \\
& & & & $(12.1)$ & $(5.11)$ & $(2.61)$ & {$[0.46]$} & {$[0.16]$} & \\
& $\mathrm{n}$ & $I_{2 t}$ & 11 & 1.018 & 0.53 & 0.27 & 12.4 & 11.8 & 85.4 \\
& & & & $(86.4)$ & $(3.36)$ & $(2.00)$ & {$[0.34]$} & {$[0.00]$} & \\
& $\mathrm{n}$ & $I_{3 t}$ & 15 & 1.019 & 0.38 & 0.04 & 17.2 & 9.2 & 109.4 \\
& & & & $(163.5)$ & $(3.16)$ & $(0.56)$ & {$[0.31]$} & {$[0.01]$} & \\
\hline USA & $\mathrm{n}$ & $I_{1 t}$ & 1 & 0.975 & 0.43 & 0.74 & 0.23 & 2.01 & N.A. \\
& & & & $(19.2)$ & $(1.62)$ & $(5.28)$ & {$[0.63]$} & {$[0.37]$} & \\
& & & & & & & \\
& $\mathrm{n}$ & $I_{2 t}$ & 11 & 1.006 & 0.36 & 0.53 & 3.18 & 11.1 & 3.24 \\
& & & & $(159.3)$ & $(2.81)$ & $(4.28)$ & {$[0.99]$} & {$[0.00]$} & \\
& $\mathrm{n}$ & $I_{3 t}$ & 15 & 1.010 & 0.23 & 0.55 & 10.51 & 10.5 & 16.0 \\
& & & & $(206.8)$ & $(3.02)$ & $(5.97)$ & {$[0.79]$} & {$[0.01]$} & \\
\hline \hline
\end{tabular}


degrees of freedom equals the number of restrictions imposed by the orthogonality conditions. These restrictions are not rejected at the $5 \%$ level for the two countries and the three different instrument sets.

- On the basis of t-tests for the parameters $\gamma_{i}$, the habit formation process appears significant in most cases and does not seem much affected by the first step (trend/notrend). Habit formation seems quantitatively more important for French imports and US domestic goods. The magnitude of their point estimates seems however to decline when we increase the number of instruments. Notice also that the point estimates of the $\gamma_{i}$ could possibly be biased downwards in the presence of some durability effects in non-durables due, e.g., to inventory holdings.

- The significance of the habit formation process based on the individual t-statistics is confirmed by the quasi likelihood ratio test statistics. Indeed, the standard life cycle model without habit formation is in most cases rejected at the $5 \%$ level.

- There is a tradeoff between $(i)$ a low point estimates of $\theta_{m}$ (which includes both the discount factor and the parameter $\mu_{d}$ or $\mu_{m}$ so that it has not to be lower than 1) and a high level of habit formation and ( $\mathrm{ii}$ ) high point estimates of $\theta_{m}$ and low habits.

\section{Parameter constancy analysis}

Lucas (1976) argued that the parameters of traditional macroeconometric models depend crucially on agents' expectations and are unlikely to remain stable in a changing economic environment. In response, econometric modelling has focused on the estimation of rational expectations models that have an explicit structural interpretation-Euler equations in particular. Thus, a natural, though little acknowledged, criterion for judging the success of empirical Euler equations is the constancy of their 'deep', structural parameters. Given the two-step analyses retained in this paper, the investigation of the constancy of the structural parameters is also pursued in two different steps. Effectively, both the longrun and the short-run parameters ought to be constant over the retained sample period if our theoretical model is to be considered as a valid representation (explanation) of the household behavior. The potential non-constancy of the curvature parameters is investigated using appropriate formal statistical tests in cointegration regression. We follow the approach proposed by Hansen (1992b), based on FMOLS estimation, under the null hypothesis of the existence of a unique cointegration vectors with constant parameters. Three different test statisitics are considered under the maintained assumption that the location of the potential break point is unkown. The first test statistic is in the spirit of traditional Chow tests: we compute a standard Chow $\mathrm{F}$ statistic for a fixed break date $t / T$ and then consider the sequence of statistics by varying the location of the break. The final statistics is then the supremum of this sequence,

$$
\operatorname{Sup} F=\sup _{t / T \in[0.15,0.85]} F_{t / T}
$$

Under $H_{0}$, SupF depends on both the number of variables in the cointegration regression and on the specification of the deterministic components. Asymptotic critical values are reported in Hansen (1992b). From the sequence of $F_{t / T}$, Hansen (1992b) also proposes to compute the average value of the $F_{t / T}$. While the null hypothesis remains the same, 
the Mean $F$ is likely to be more powerful against gradual changes in the parameters. Finally, as shown in Table 2, we also compute Hansen's $L_{c}$ test statistic for parameter constancy against martingale variation in the constant term of the cointegration regression. Although formally built as a test for parameter constancy, $L_{c}$ is easily interpreted as testing the null of cointegration. Figure 1 reports the sequence of $F_{t / T}$ over the interval $[0.15,0.85]$. From these figures, we may not reject the constancy of the long-run parameters for both countries. This provides an additional argument in favour of the long-run implications of the theoretical model.

Given that we cannot reject the constancy of the long-run parameters, we may analyse the constancy of the short-run parameters conditionally on this. The analysis considers a sequence of $L R$ tests, see Andrews (1993), computed as the difference between the partialsample GMM objective function evaluated at the full sample GMM and at the partial sample-GMM estimators. The structural break is allowed to occur in the interva ${ }^{12}$ of time $[0.25,0.75]$. The test can be performed for the two larger instrument sets which provide enough overidentifying restrictions. Figure 2 presents the sequences of the $L R_{t / T}$ statistics. We first note that the parameter constancy hypothesis is rejected for France whatever instrument sets are used. For the USA, we observe some moderate ${ }^{13}$ nonconstancy with the larger set $I_{3 t}$. However, it is likely that $I_{3 t}$ is too large given the size of the sub-sample used in the computation of $L R_{t / T}$. With $I_{2 t}$, which is less subject to the above criticism, the parameter constancy cannot rejected for the USA.

To evaluate the role of habit formation, we have also tested the parameter constancy of the standard life-cycle model (without habits) for the USA. This is reported in the third panel of Figure 2. Clearly, the constancy of the parameters is now rejected. The parameters seem to have experienced a shift during the period 78-81, which may correspond to the change in monetary policy of these years. This shows that the introduction of habit formation is important in obtained a well specified model of imports, at least for the USA.

A remaining issue is the observed non-constancy of the short-run parameters for France. Although not reported, partial-sample estimates of the parameters indicate that the rate of time preference increases substantially at the end of the period. Among the potential explanations of this phenomenon, we could argue that our model should display endogenous discount rates. Indeed, a rise in the discount rate is consistent with the idea of Uzawa (1968) that a higher level of consumption implies a higher rate of time preference. This is however difficult to defend a priori, since we usually think that the rich is more patient than the poor. An alternative explanation could be a too high aggregation level. It should be interesting to investigate whether different goods have experienced very different evolutions in their prices, and whether the weight of these goods in the consumer basket has changed over the sample period. Effectively, observed parameter non-constancy may reveal heterogeneity in preferences, in goods or in initial wealth endowments (Fève and Langot, 1995).

\footnotetext{
${ }^{12}$ For numerical reasons linked to the non-linear structure of our second-step problem, it was necessary to reduce the interval of time compared to the one used in the first step.

${ }^{13}$ The constancy is rejected at $5 \%$, but not at $1 \%$.
} 
Figure 1: Constancy of the cointegration parameters model without trend - France
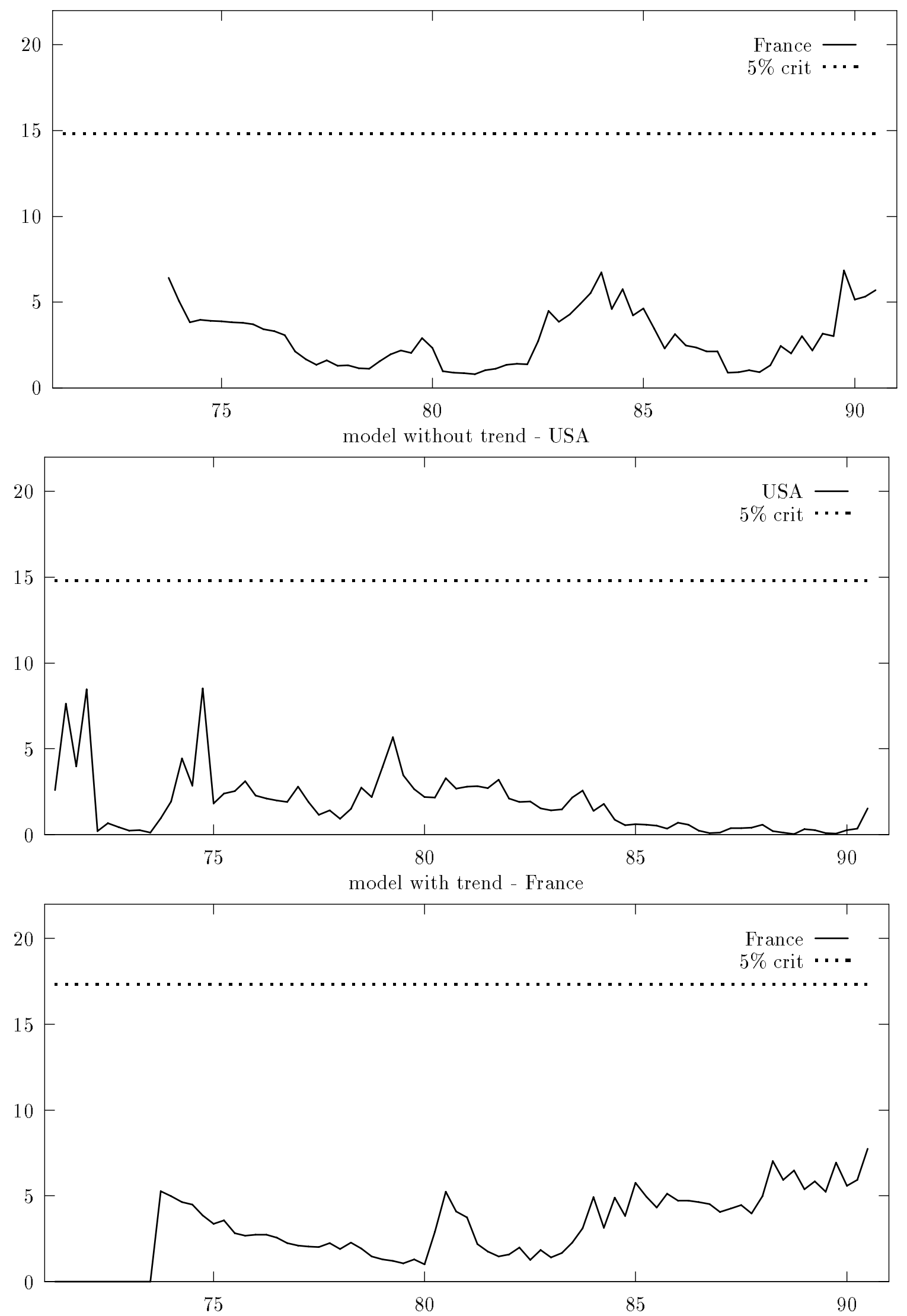
Figure 2: Constancy of the parameters estimated by GMM France
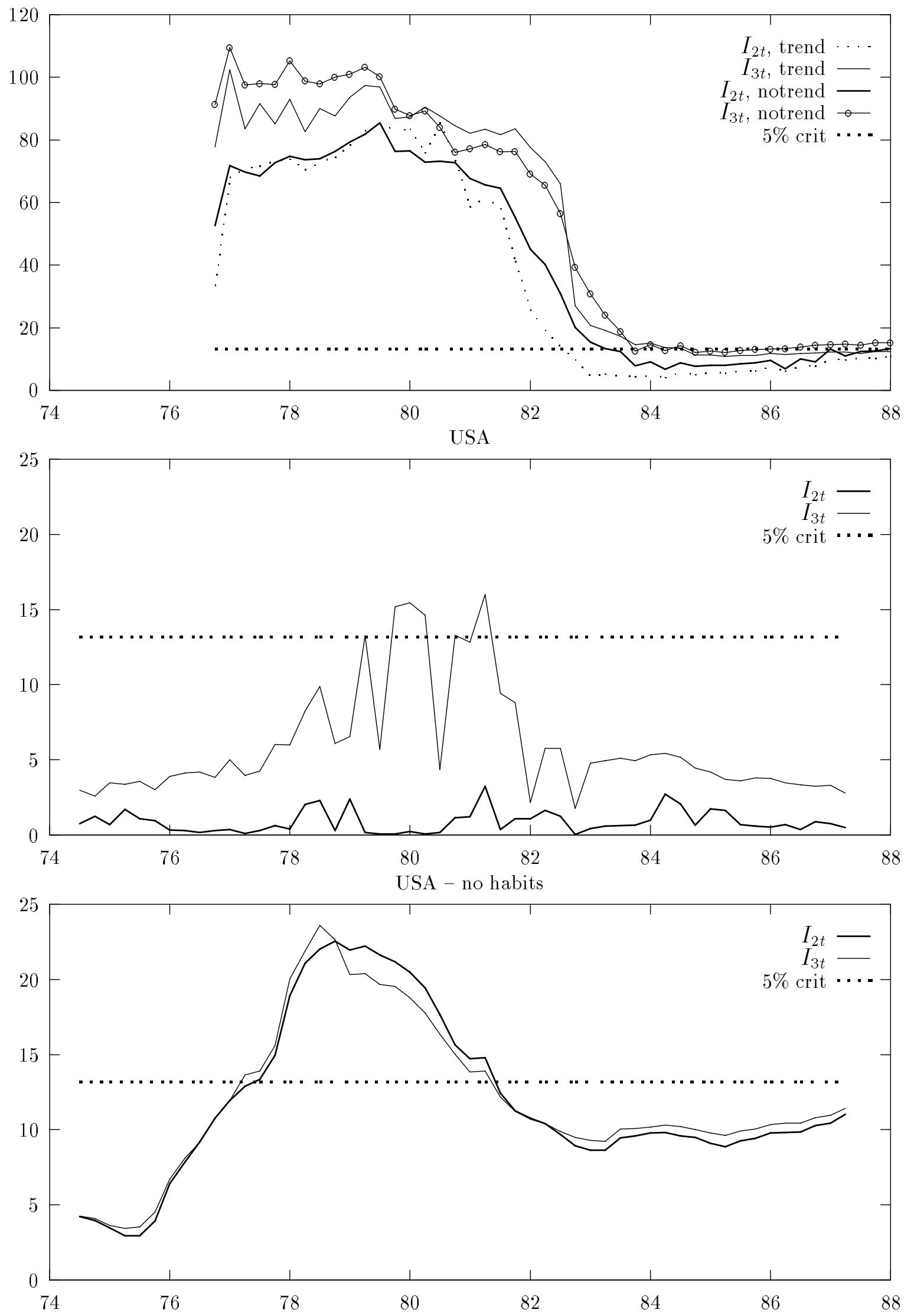


\section{Conclusion}

The purpose of this paper was to study non-durable imports demand, by extending previous work done by Clarida (1994) and Ceglowski (1991). We considered a two-good version of the life cycle model in which we introduce time-nonseparability in the households' preferences. The model is estimated using quarterly time series data for US and France. Using the information contained in the observed stochastic and deterministic trends, we derive a cointegration restriction used to estimate curvature parameters of the instantaneous utility function. The remaining parameters are estimated in a second step by GMM. Table 4 compares our results (without trend in the long-run) with those obtained in other studies.

Let us first consider the parameters $1 / \alpha_{i}$, which are related to the willingness of consumers to shift consumption across time in response to changes in interest rates. The bulk of empirical evidence suggests a relatively low value of this elasticity of substitution, lying around or below unity. For the USA, our estimates confirm a large and significant long-run elasticity of intertemporal substitution for imports, three times larger than the one for domestic goods. One implication of this is the importance of real interest rates for determining the consumer demand for imports. As already pointed out in the introduction, this contrasts sharply with standard import equations. For France, the elasticities are less important, but the elasticity for imports is still four times larger than the one for domestic goods. Thus, the French estimates confirm that imports are more sensitive to changes in interest rate than domestic goods. Although the finding of a relatively large elasticity of intertemporal substitution for non-durable imports as compared to domestic consumption cannot easily be accounted for by the consumer theory, one potential explanation could be the lower share of necessities in imports. ${ }^{14}$ An interesting empirical finding is the constancy of the curvature parameters for both countries.

Considering now the implications of the model in terms of the nonlinear dynamics, an important result is that the overidentifying restrictions implied by the habit formation assumption are not rejected by the data. The habit formation process seems particularly significant. On the one hand, the alternative model without habit formation is strongly rejected on the basis of quasi-likelihood ratio tests. On the other hand, the introduction of habits is usefull for the constancy of the short-run parameters for the USA. These results support the view that ignoring habits may explain the frequent rejection of the life cycle hypothesis.

The estimation of the habit formation process is however not fully convincing. The point estimates of the parameters are sensible to the chosen instrument set. The constancy of the short-run parameters is rejected for France. In some cases one finds a relatively weak effect of habits. One potential extention of this work is to investigate whether richer (non-linear) forms of habit formation, as e.g. in Campbell and Cochrane (1995) or Lettau and Uhlig (1995), could not improve or modify our conclusions. In particular, it may provide an explanation for the observed non-constancy for France.

\footnotetext{
${ }^{14}$ The question whether the inventory behaviour of the importers can be responsible for the higher inter-temporal elasticity of substitution of imports is left for future research.
} 


\begin{tabular}{|c|c|c|c|c|c|c|}
\hline & \multicolumn{2}{|c|}{ This paper } & Clarida & Ceglowski & Ogaki-Park & Ferson-Constantinides \\
\hline country & France & U.S. & U.S. & U.S. & U.S. & U.S. \\
\hline sample & $70-94$ & $67-94$ & $67-90$ & $67-88$ & $47-89$ & $48-86$ \\
\hline \multirow[t]{2}{*}{$1 / \alpha_{m}$} & 0.41 & 0.75 & 0.95 & 0.89 & & \\
\hline & & & & & 0.43 & 0.67 \\
\hline $1 / \alpha_{d}$ & 0.10 & 0.27 & 0.44 & 0.33 & & \\
\hline \multirow[t]{2}{*}{$\gamma_{m}$} & 0.53 & 0.36 & - & - & & \\
\hline & & & & & 0.19 & 0.28 \\
\hline$\gamma_{d}$ & 0.27 & 0.53 & - & - & & \\
\hline
\end{tabular}

\section{Appendix: data sources}

For France, the source is Comptes nationaux trimestriels (INSEE). The data on nondurables include subsectors U02 (meet and milk products, other products from food industry) and U06 (drugs, textiles, clothing, shoes, leather, furnitures, printing). The interest rate is: taux de l'argent au jour le jour des effets privés.

For the USA, both the source and the construction of the data follow Ceglowski (1991) for an extended sample size. The interest rate is the three month treasury bill rate.

\section{References}

Andrews, D. (1993) "Test for parameter instability and structural change with unknown change point". Econometrica, 61:821-856.

Andrews, D. and C. Monahan (1992) "An improved heteroscedasticity and autocorrelation consistent covariance matrix". Econometrica, 60:953-966.

Argyle, M. (1987) The psychology of happiness. Methuen.

Asseery, A. and D. Peel (1991) "Estimates of a traditional aggregate import demand model for five countries". Economic Letters, 35:435-439.

Campbell, J. and J. Cochrane (1995) "By force of habits: a consumption-based explanation of aggregate stock market behavior". Technical Report, NBER.

Canova, F., M. Finn and A. Pagan (1992) "Evaluation a real business cycle model". Technical Report, European University Institute. 
Cappucio, N. and D. Lubian (1994) "Fully modified estimation of cointegrating vectors via VAR prewhitening: a simulation study". Technical Report, University of Padoua.

Ceglowski, J. (1991) "Intertemporal substitution in import demand". Journal of International Money and Finance, 10:118-130.

Clarida, R. (1994) "Cointegration, aggregate consumption, and the demand for imports: A structural econometric investigation". American Economic Review, 84:298-308.

Dickey, D. and W. Fuller (1979) "Distribution of the estimators for autoregressive time series with a unit root". Journal of the American Statistical Association, 74:427-431.

Duesenberry, J. (1949) Income, saving, and the theory of consumer behavior. Harvard University Press.

Eichenbaum, M., L. Hansen and K. Singleton (1988) "A time series analysis of representative agent models of consumption and leisure choice under uncertainty". Quarterly Journal of Economics, 103:51-78.

Engle, R. and C. Granger (1987) "Co-integration and error correction: representation, estimation and testing". Econometrica, 55:251-276.

Ferson, W. and G. Constantinides (1991) "Habit persistence and durability in aggregate consumption". Journal of Financial Economics, 29:199-240.

Fève, P. and F. Langot (1995) "La méthode des moments généralisées et ses extensions". Economie et Prévision, 119:139-169.

Gagnon, J. (1988) "Adjustments costs and international trade dynamics". Journal of International Economics, 26:327-344.

Gallant, D. (1987) Nonlinear statistical models. Wiley.

Goldstein, M. and M. Khan (1985) Income and price elasticities in foreign trade. In Handbook of International Economics, Vol. 2. North Holland.

Hall, A. (1993) Some aspects of generalized method of moments estimation. In G. Maddala, C. Rao and H. Vinod, editors, Handbook of Statistics, Vol. 11. Elsevier.

Hansen, B. (1992a) "Tests for parameter instability in regressions with I(1) processes". Journal of Business and Economic Statistics, 10:321-335.

Hansen, B. (1992b) "Efficient estimation and testing for cointegration vector with the presence of deterministic trends". Journal of Econometrics, 53:81-121.

Hansen, L. (1982) "Large sample properties of generalized method of moments estimators". Econometrica, 50:1029-1054.

Hansen, L. and K. Singleton (1982) "Generalized instrumental variables estimation of nonlinear rational expectations models". Econometrica, 50:1269-1286.

Haug, A. (1995) “Tests for cointegration: a Monte Carlo comparison". Journal of Econometrics, forthcoming.

Helson, H. (1964) Adaptation-level theory: an experimental and systemic approach to behavior. Harper and Row.

Husted, S. and T. Kollintzas (1987) "Linear rational expectations equilibrium laws of motion for selected U.S. raw material imports". International Economic Review, 28:651670. 
Johansen, S. (1991) "Estimation and hypothesis testing of cointegration in vector Gaussian autoregressive models". Econometrica, 59:1551-1580.

Kim, Y. (1993) "Frisch demand functions and intertemporal substitution in consumption". Journal of Money, Credit and Banking, 25:445-454.

Kitamura, Y. and P. Phillips (1994) "Fully modified IV, GIVE and GMM estimation with possibly non-stationary regressor and instruments". Technical Report, Cowles foundation.

Kocherlakota, N. (1990) "On tests of representative consumer asset pricing models". Journal of Monetary Economics, 26:285-304.

Kollintzas, T. and S. Husted (1984) "Distributed lags and intermediate goods imports". Journal of Economic Dynamic and Control, 8:303-327.

Lettau, M. and H. Uhlig (1995) "Can habit formation be reconciled with business cycle facts?" Technical Report, CentER (Tilburg).

Lucas, R. (1976) Econometric policy evaluation: a critique. In K. Brunner and A. Metzler, editors, The Phillips Curve and Labour Market. North-Holland, Carnegie-Rochester Conference Series on Public Policy.

MacKinnon, J. (1991) Critical values for cointegration. In R. Engle and C. Granger, editors, Long-run Economic Relationships: Readings in Cointegration. Oxford University Press.

Mah, J. (1994) "Japanese import demand behaviour: the cointegration approach". Journal of Policy Modeling, 16:291-298.

McLaughlin, K. (1995) "Intertemporal substitution and $\lambda$-constant comparative static". Journal of Monetary Economics, 35:193-213.

Muellbauer, J. (1988) "Habits, rationality and myopia in the life cycle consumption function". Annales d'Economie et de Statistique, 9:47-70.

Nelson, C. and R. Startz (1990) "The distribution of the instrumental variable estimator and its t-ratio when the instrument is a poor one". Journal of Business, 63:125-140.

Newey, W. and K. West (1987) "A simple positive definite, heteroskedasticity and autocorrelation consistent covariance matrix". Econometrica, 55:703-708.

Ogaki, M. (1992) "Engel's law and cointegration". Journal of Political Economy, 100:1027-1046.

Ogaki, M. (1993a) Generalized method of moments: Econometric applications. In Maddala, Rao and Vinod, editors, Handbook of Statistics, Vol. 11. Elsevier.

Ogaki, M. (1993b) "Unit roots in macroeconomics: A survey". BOJ Monetary and Economic Studies, 2:131-154.

Ogaki, M. and J. Park (1994) "A cointegration approach to estimating preference parameters". Technical Report, University of Rochester.

Otto, G. (1992) "Testing a present-value model of the current account: Evidence from us and canadian time series". Journal of International Money and Finance, 11:414-430. Park, J. (1990) "Testing for unit roots and cointegration by variable addition". Advances in Econometrics, 8:107-133. 
Phillips, P. and B. Hansen (1990) "Statistical inference in instrumental variables with I(1) processes". Review of Economic Studies, 57:99-124.

Phillips, P. and P. Perron (1988) "Testing for a unit root in time series regression". Biometrika, 75:335-346.

Schmidt, P. and P. Phillips (1992) "LM tests for a unit root in the presence of deterministic trends". Oxford Bulletin of Economics and Statistics, 54:257-287.

Urbain, J.-P. (1992) Error correction models for aggregate imports. In M. Dagenais and P.-A. Muet, editors, International Trade Modelling. Chapman and Hall.

Urbain, J.-P. (1995) "Partial versus full system modelling of cointegrated systems: An empirical illustration". Journal of Econometrics, 69:177-210.

Uzawa, H. (1968) Time preference, the consumption function and optimum asset holdings. In Value, Capital and Growth: Papers in Honour of Sir John Hicks. University of Edinburgh Press.

Winder, C. and F. Palm (1992) "Stochastic implications of the life cycle consumption model under rational habit formation". Technical Report, University of Limburg. 